ISSN 0103-5150

Fisioter. Mov., Curitiba, v. 25, n. 4, p. 737-746, out./dez. 2012

Licenciado sob uma Licença Creative Commons

\title{
Discurso de fisioterapeutas acerca da comunicação com sujeitos com encefalopatia crônica não progressiva
}

\author{
Discourse of physiotherapists on the communication with \\ subjects with chronic non-progressive encephalopathy
}

\section{Francine Manara Bortagarai ${ }^{[a]}$, Ana Paula Ramos ${ }^{[\mathrm{b}]}$}

[a] Especialista em Fisioterapia Geriátrica e Gerontológica, mestre do Programa de Distúrbios da Comunicação Humana do curso de Fonoaudiologia da Universidade Federal de Santa Maria (UFSM), Santa Maria, RS - Brasil, e-mail: fbortagarai@hotmail.com

[b] Professora adjunta do curso de Fonoaudiologia da Universidade Federal de Santa Maria (UFSM), Santa Maria, RS - Brasil, e-mail: ramos1964@uol.com.br

\section{Resumo}

Introdução: A Encefalopatia Crônica Não Progressiva (ECNP) refere-se ao prejuízo motor não evolutivo, adquirido antes dos dois primeiros anos de vida, que manifesta desordem do movimento e da postura. Além do atraso nas aquisições motoras, o sujeito acometido por essa patologia pode apresentar problemas de visão, cognição, comunicação e comportamento, dependendo da gravidade do comprometimento neurológico. Para tanto, há a necessidade de uma equipe de profissionais da área da saúde para auxiliá-lo e de uma visão humanista em seu atendimento. Objetivo: Analisar as formas de comunicação utilizadas entre fisioterapeutas e sujeitos com encefalopatia crônica não progressiva (ECNP). Materiais e métodos: Foram realizadas entrevistas individuais com perguntas abertas pertinentes à temática. A análise dos dados ocorreu com a seleção e o agrupamento das ideias mais relevantes sobre o tema a partir de análise crítica e relacional. Resultados: A forma de comunicação não verbal mais referida pelos fisioterapeutas foi a cinésica (expressão facial e corporal), enfatizada como importante e presente na sessão de fisioterapia com o sujeito com ECNP. 0 grupo investigado afirma ter dificuldades na interpretação da leitura corporal desses sujeitos. A abordagem de tal tema demonstrou-se deficitária na vida acadêmica de grande parte dos fisioterapeutas investigados. Do mesmo modo, há quase um desconhecimento dos benefícios de outras formas 
de comunicação, como a comunicação aumentativa alternativa (CAA). Conclusão: Os resultados sugerem a necessidade de se ampliar a formação de fisioterapeutas em relação à comunicação dentro de uma perspectiva de maior humanização do atendimento a sujeitos com ECNP.

Palavras-chave: Comunicação. Fisioterapia. Encefalopatia. Humanização.

\begin{abstract}
Introduction: Non-Progressive Chronic Encephalopathy (NPCE) refers to motor damage acquired before the first two years of life which is not evolutionary, which manifests movement and posture dysfunction. Besides the delay in motor acquisition, the subject affected by this pathology can present problems with vision, cognition, communication and behavior, depending on the severity of the neurological deficit. Therefore, there is the need for a team of health professionals to assist this patient as well as the need of a humanistic view on this service. Objective: To analyze the discourse of physiotherapists on their way of communicating with subjects with chronic non-progressive encephalopathy (CNPE). Materials and methods: Individual interviews with open questions were conducted on the theme. Data analysis was done by selecting and grouping the most relevant ideas about the topic through critical and relational analysis. Results: Although non-verbal communication mentioned by the physiotherapists through kinesics (facial and body expression) has been emphasized as important and present in the physiotherapy session with subjects with CNPE, the group claim having problems in interpreting the body language of these subjects. This topic seems to have been neglected in the academic life of most of the investigated physiotherapists. Likewise, there is a kind of lack of knowledge of the benefits of using alternative and augmentative communication (AAC). Conclusion: The results suggest the need of expanding the training of physiotherapists in relation to communication within a perspective of a greater humanization of services to subjects with NPE.
\end{abstract}

Keywords: Communication. Physiotherapy. Encephalopathy. Humanization.

\section{Introdução}

Encefalopatia crônica não progressiva (ECNP) é o termo utilizado, atualmente, para designar o transtorno conhecido como paralisia cerebral (PC), distúrbio do movimento e da postura que resulta de lesão cerebral ocorrida no período inicial do desenvolvimento infantil (1). 0 sujeito acometido por essa patologia pode apresentar problemas de visão, cognição, comunicação, comportamento, movimento e postura, dependendo da gravidade do comprometimento neurológico (2). Essa desordem no movimento faz com que essas crianças tenham um curso do desenvolvimento motor anormal, apresentando atraso nas aquisições motoras (3).

A procura por diferentes técnicas de reabilitação que possibilitem ganhos funcionais é uma constante na pesquisa clínica da ECNP. Vários são os estudos enfocando as formas de intervenção em que a reabilitação do indivíduo com lesão no sistema nervoso se volte para sua capacitação funcional $(4,5)$ e sua qualidade de vida (6).
Dentro da equipe multidisciplinar que deve assistir o sujeito com ECNP, enfatiza-se o trabalho do fisioterapeuta. As intervenções motoras propostas por esse profissional têm por objetivo um melhor desempenho das habilidades funcionais, por meio da facilitação de padrões normais de movimento, melhora na flexibilidade e nas capacidades motoras básicas (3).

Vários métodos de tratamento vêm sendo desenvolvidos a partir de fundamentações neurofisiológicas, destacando-se o método de Bobath, que se baseia na inibição dos reflexos primitivos e dos padrões patológicos de movimentos; o método de Phelps, que se fundamenta na habilitação por etapas dos grupos musculares, até chegar à independência motora e às práticas complexas, e o método de Kabat, baseado na utilização de estímulos proprioceptivos facilitadores das respostas motoras, partindo de respostas reflexas e chegando à motricidade voluntária (7).

Associado ao distúrbio motor, base do quadro clínico, está uma série de outros sintomas, como deficiência mental, epilepsia, transtornos auditivos, oculares, visuais, de conduta e de linguagem (8), o 
que demanda também a atenção de outros profissionais da área da saúde.

Com relação aos distúrbios de linguagem que essa criança pode vir a apresentar, estudos demonstram que a eclosão das várias etapas do desenvolvimento linguístico, nos sujeitos com ECNP com alterações motoras severas, aparece, frequentemente, mais tardiamente, quando comparados com a população normal (9). Os transtornos da linguagem do tipo disfásico ou disártrico são muito frequentes (10). Diante de tais dificuldades da criança com ECNP, as carências motoras ganham maior evidência e muitos profissionais esquecem que, naquele corpo deficiente, há um sujeito que pode se comunicar por outras vias que não a da articulação oral. Ele pode comunicar suas emoções, seus conhecimentos e seus afetos, ou seja, a "linguagem" não se reduz à fala articulada. Outras modalidades da linguagem, que não a oral, são as expressões corporais e faciais e os sistemas gráfico-visuais (11).

Dentre os sistemas gráfico-visuais, estão os recursos tecnológicos assistidos, como a comunicação aumentativa e alternativa (CAA), utilizada nos casos em que os sujeitos apresentam uma linguagem receptiva preservada, mas com oralidade ausente ou restrita. Seus benefícios são demonstrados em pesquisas como a de Paula e Enumo (12), e sua aplicabilidade e seus benefícios durante a sessão são demonstrados conforme estudo de Cesa et al. (13). A utilização desses recursos produz um sujeito com ECNP mais ativo e participante, o que torna a terapia mais prazerosa e com melhores resultados (10).

Ocorre, então, a discutida humanização em saúde, por meio da qual se objetiva que os acadêmicos e os profissionais da área reconheçam o indivíduo/ paciente como um todo físico-psíquico-biológico e social (14-19). No entanto, a dificuldade de atingir essa visão integral do sujeito em tratamento pode ser justificada tanto pelo ensino quanto pela prática da fisioterapia, que ainda segue os modelos adotados pela Medicina: a fragmentação do ser humano, a divisão em especialidades, a ênfase na cura e a reabilitação e o tecnicismo, amparados pelo modelo da física clássica (20-22).

Espera-se que na abordagem atual da fisioterapia motora, a pessoa com deficiência seja considerada um ser funcional e social (23). 0 desafio estabelecido está em transformar essas concepções conceituais em práticas de intervenção (24); a comunicação torna-se, portanto, um elemento-chave nesse processo. Para tanto, o fisioterapeuta deverá enfocar esse tema em sua perspectiva terapêutica $(14,18)$.

Tendo em vista a importância atribuída ao trabalho do fisioterapeuta com sujeitos com ECNP e as propostas de humanização dos serviços dos profissionais da saúde, este estudo teve como objetivo investigar o que fisioterapeutas dizem a respeito da comunicação, durante a sessão, com o sujeito com ECNP que não oraliza ou apresenta dificuldades na efetuação da fala.

\section{Materiais e métodos}

Admitiram-se, na pesquisa, fisioterapeutas que interviessem na clínica com sujeitos com ECNP, com experiência clínica de no mínimo um ano. A amostra foi de conveniência e constituída por 12 voluntários de diferentes centros de reabilitação.

Após a explicação dos objetivos e procedimentos da pesquisa, e da assinatura do termo de consentimento livre e esclarecido, foi iniciada a aplicação de um roteiro de entrevista pela pesquisadora, o qual foi elaborado, com perguntas abertas. A temática das perguntas foi pertinente à abordagem acadêmica da comunicação com o sujeito com ECNP, das formas de comunicação e interpretação corporal das produções desse sujeito e dos conhecimentos de leitura corporal e da comunicação aumentativa alternativa (CAA). Esse roteiro auxiliou a coleta de dados e, conforme o desenvolvimento da narrativa, a pesquisadora poderia realizar outras questões, não se limitando somente aos questionamentos traçados no guia de entrevista inicial. Todas as entrevistas foram gravadas em um aparelho de marca Sony TCM 359V, em fitas cassetes, tendo cada entrevista duração média de uma hora. Ao término da coleta, as fitas foram submetidas à transcrição pela própria pesquisadora. A coleta de dados foi realizada de maio a julho de 2010.

A partir da transcrição integral das fitas e da leitura do material, realizou-se a análise dos dados, conforme a análise temática de Minayo (25). Houve o cuidado com os recortes a serem feitos, para extrair dos depoimentos os elementos mais significativos, sem alterá-los, transcrevendo-os tais como foram apresentados. Desse modo, buscou-se identificar as semelhanças e diferenças entre os discursos dos fisioterapeutas, assim como as contradições, e sinalizar significados latentes nas entrevistas. Foram selecionadas partes do material, as quais foram agrupadas de acordo com a semelhança dos relatos dos 
entrevistados, realizando, assim, recortes temáticos de forma a desenvolver a análise crítica e relacional dos dados obtidos para revelar as respostas aos questionamentos abordados (25).

Esta pesquisa foi aprovada pelo Comitê de Ética em Pesquisa Institucional, sob processo n. 23081.013051/2009-91 e Certificado de Apresentação para Apreciação Ética - CAAE n. 0223. 0.243.000-09.

No decorrer do artigo será utilizada a designação "F" (fisioterapeuta), seguida da numeração arábica correspondente (F1, F2 etc.), para fazer referência aos informantes e facilitar a referência aos enunciados.

\section{Resultados}

A amostra foi composta por três fisioterapeutas do sexo masculino e nove do sexo feminino.

Pode-se perceber que apenas quatro participantes tinham mais de cinco anos de experiência profissional e que a maior parte ficou entre um e quatro anos e meio.

Quadro 1 - Perfil da amostra de fisioterapeutas quanto à variabilidade de instituição de formação acadêmica (sete instituições), ao tempo de graduação e de atuação profissional

\begin{tabular}{llll}
\hline $\begin{array}{l}\text { Sujeitos } \\
\text { entrevistados }\end{array}$ & $\begin{array}{l}\text { Instituição } \\
\text { de formação } \\
\text { acadêmica }\end{array}$ & $\begin{array}{l}\text { Tempo de } \\
\text { graduação }\end{array}$ & $\begin{array}{l}\text { Tempo de } \\
\text { atuação } \\
\text { profissional }\end{array}$ \\
\hline F1 & A & 9 anos & 9 anos \\
F2 & B & 12 anos & 12 anos \\
F3 & B & 10 anos & 10 anos \\
F4 & C & 3 anos & 2 anos e meio \\
F5 & C & 1 ano & 1 ano \\
F6 & B & 3 anos & 2 anos \\
F7 & D & 2 anos & 2 anos \\
F8 & E & 1 ano e meio & 1 ano e meio \\
F9 & E & 3 anos & 3 anos \\
F10 & D & 12 anos & 12 anos \\
F11 & F & 4 anos & 4 anos \\
F12 & G & 5 anos & 4 anos e meio \\
\hline
\end{tabular}

Fonte: Dados da pesquisa.
Quanto ao questionamento referente à abordagem de disciplinas de comunicação com o sujeito, em geral, e com o ECNP, em particular, a maioria dos fisioterapeutas relata não ter visto essa temática nem disciplina específica durante a aprendizagem acadêmica (F1, F2, F3, F4, F7, F9, F10); uma afirmou ter estudado o tema de modo introdutório (F8) e três relataram o enfoque dessa temática em outras disciplinas, por exemplo: Psicologia (F12), Fisioterapia Aplicada e Neurologia 1 (F11) e na Fisioterapia na Criança (F5).

Predomina, portanto, na formação acadêmica do grupo amostral, a ausência de um planejamento específico sobre o tema da comunicação com sujeitos com ECNP, o que pode ser visualizado nos depoimentos de F11 e F5:

Esse tema, se eu bem recordo, não tinha um planejamento no conteúdo programático da disciplina, apenas a professora da parte prática comentava sobre os recursos de comunicação em tecnologia assistida e suas experiências na clínica com seus pacientes [...] (F11).

Abordava mais tu prestar atenção na criança, fazer um código entre fisio e ela [...] aí tu vai fazendo um diálogo específico teu e do paciente (F5).

Quanto à forma como os fisioterapeutas se comunicam com o sujeito com ECNP durante a sessão de fisioterapia, a maioria relatou a comunicação não verbal por meio da expressão corporal (gestos) e facial (olhar, mímica facial), além da utilização de objetos (coloridos e sonoros) no auxílio (F1, F2, F3, F4, F5, F6, F7 e F10), conforme observamos em alguns depoimentos. F1 afirma ser olho no olho; F2 cita olhar, gestos, objetos barulhentos; F3 resume como fala pausada e próxima a criança, objetos sonoros e coloridos.

Além da comunicação não verbal citada por esses fisioterapeutas, apenas um pequeno grupo de fisioterapeutas que conhece e utiliza a CAA citou a prancha com figuras simbólicas como outra forma de se comunicar com o sujeito com ECNP que apresenta dificuldade ou não oraliza (F8, F9, F12). A CAA possibilita aos sujeitos irem além da resposta "sim" ou "não" efetuada com a cabeça, pois permite que consigam contar mais de sua rotina, como relatado por F8: A primeira coisa que a gente pergunta é o sim e o não, mas quando eles querem contar uma coisa mais específica, tem uns 
que já explicam direitinho no símbolo, que pedem direitinho para virar a pasta (F8).

A limitação do uso da prancha na água é relatada pelo F10: tentei fazer figuras com contact, mas não deu certo, molhavam na água.

Os 12 fisioterapeutas relataram fazer a interpretação corporal do sujeito com ECNP. Alguns ressaltaram a importância da interação e do convívio com esse sujeito para facilitar a leitura desses sinais: [...] às vezes um piscar de olho já quer dizer alguma coisa, $e$ com o passar do tempo tu aprende a conhecer muitos sinais [...] e informações durante a sessão (F1); É bem difícil, não é uma coisa fácil [...]. Tu vai pegando um pouco do jeito, sabe algumas respostas quando ele não gosta ou a expressão facial [...] pelas reações do corpo dele (F4); Quando tu tá pegando um paciente inicial é bem complicado porque tu tem que ter um pouco mais de intimidade com ele para perceber qual é a feição dele da dor, do cansaço, da euforia [...] (F5); Pelo convívio tu acaba percebendo o que faz bem [...] o que faz mal [...] (F6).

Outros citam uma interpretação das reações corporais dos sujeitos com ECNP com oralidade restrita ou ausente embasada em situações de desconforto e choro: [...] se vejo que o paciente chora paro um pouquinho, tento mudar de posição ou se ele está muito estressado, mostro outras coisas [...] (F2); Se for choro, eu tento saber o porquê, se é dor [...] (F7).

E há, também, a citação das reações corporais desse sujeito baseadas nas repostas fisiológicas próprias da patologia: A hipertonia reflexa você interpreta como se a criança não está receptiva no momento (dificuldade e tensão ao responder) (F3); Algumas reações corporais são mais exacerbadas no corpo com alterações no tônus muscular e/ou atividade reflexa anormal comunicando sensações e emoções (F11).

Embora todos os fisioterapeutas do grupo amostral, conforme relatado acima façam a interpretação das reações corporais do sujeito com ECNP com oralidade restrita ou ausente, os fisioterapeutas investigados confirmam a dificuldade na interpretação dos gestos corporais desses sujeitos (F2, F3, F4, F5, F6, F7, F8, F9, F10, F11, F12). As dificuldades dessa interpretação estão relacionadas ao pouco tempo de vínculo com o sujeito, principalmente nas sessões iniciais, a dificuldade da "leitura" da dor e das necessidades fisiológicas. Por meio dos seguintes discursos, podemos exemplificar algumas das dificuldades: Quanto tu tá pegando um paciente inicial, é bem complicado porque tem que ter um pouco mais de intimidade com ele para poder perceber qual é a feição dele da dor, da alegria, do cansaço, da euforia [...] (F5); Tenho dificuldades para saber o ponto de dor do paciente [...] (F7); Achei que a paciente estava com dor no quadril, mas na realidade ela queria me dizer que estava menstruada e com cólicas (F10); Sinto dificuldade quando o paciente necessita e quer expressar uma conversa mais elaborada e subjetiva, mas não dispõe de recursos para isso (F11).

Em oposição aos demais, F1 afirma não ter dificuldades na interpretação dos gestos corporais do sujeito com ECNP com oralização restrita ou ausente: [...] às vezes [...] pela forma como ele está entrando ali a gente já sabe como está a parte do bom humor dele, se ele está tenso, se está preocupado (F1).

Mesmo com esse deficit na interpretação corporal, demonstrado pela maioria dos fisioterapeutas, todos concordam quanto à importância da compreensão da comunicação não verbal e verbal do sujeito com ECNP com oralização difícil ou ausente. Essa interpretação norteia os limites e a evolução da sessão, segundo a maioria dos profissionais. Os recortes dos dizeres dos fisioterapeutas a seguir ilustram esse aspecto: sem essa compreensão fica mais difícil e demorada a evolução do tratamento (F7); [...] não adianta a gente só ir lá e dobrar e esticar a criança [...] e não ter a compreensão do que ela quer [...] (F8).

Indagados sobre seu entendimento a respeito da leitura corporal, os fisioterapeutas a descreveram de distintos modos:

- Condicionada à situação momentânea do sujeito atendido: [...] o corpo se manifesta de várias formas, da forma como tu tá naquele dia [...] (F1); [...] interpretar através de gestos da criança o comportamento dela no momento [...] (F3); [...] é tu conseguir perceber no ambiente que tu tá atendendo o paciente, o momento que ele tá vivendo [...] (F5).

- Sujeita à má interpretação: [...] às vezes você pode fazer uma leitura errada, uma má impressão num primeiro momento daquela pessoa... pensa que ela tá fechada [...], mas às vezes isso é timidez (F1).

- Vinculada à leitura de manifestações corporais semivoluntárias (os sujeitos tentam se expressar voluntariamente, mas o fazem por reflexos): étu saber interpretar os movimentos, aumento do tônus quando ficam mais nervosos 
[...] (F2); Toda e qualquer expressão corporal que ele tem como resposta ao estímulo [...] (F4); [...] é olhar a criança que, por exemplo, tá deitada e dizer que ela tem uma deficiência, um encurtamento [...] (F8).

- Manifesta por meio de comunicação não verbal cinésica - expressão corporal e facial (F3, F5, F6, F7, F9, F10) -, sendo a leitura corporal entendida como a interpretação da criança por gestos e expressões corporais. Uma das entrevistadas relata que:

[...] tu conseguir perceber como o corpo dele começa a se comunicar contigo, o rosto, os olhos, as mãos, uma relação bem íntima [...]. Alguns pacientes não têm essa intimidade com o próprio corpo, fica difícil se comunicar [...] depende bastante da consciência corporal do paciente e do "feeling" do fisioterapeuta [...] (F5).

- Como expressão de estado emocional: São mensagens que o corpo transmite além do que as palavras podem comunicar (F11); É a maneira como o corpo vai expressar algum sentimento, alguma vontade, um estado da pessoa (F12).

E, finalmente, ao serem questionados sobre o conhecimento e a utilização da CAA com os sujeitos com ECNP com oralização restrita ou ausente, durante a sessão de fisioterapia, F1, F2, F3 não a conhecem nem a utilizam, sendo que F1, formada há nove anos e trabalhando com crianças com essa patologia, demonstrou espanto em seu discurso: Não, eu nunca trabalhei com isto. 0 quê que é? F2, formada há 12 anos: Não conheço, não sei o que é; e F3, formada há dez anos: Não conheço.

Já F4, F5, F6, F7 conhecem a CAA, porém não a utilizam. F5 relatou que tal recurso foi abordado teoricamente, mas que nunca manuseou uma prancha de Comunicação Aumentativa Alternativa. A partir da explicação breve dada pela pesquisadora, sobre esse recurso, F5 manifestou o desejo de conhecer mais: achei uma coisa bem interessante e a partir de agora vou tentar começar até a encaminhar os pacientes pra fono pra tentar fazer e melhorar a comunicação com o paciente (F5).

O conhecimento e o uso da CAA independem do tempo de formação acadêmica dos fisioterapeutas, o que significa que não necessariamente o fisioterapeuta mais jovem em formação domine melhor esse recurso. Neste estudo, F10, um dos profissionais de mais antiga formação (12 anos), utiliza esse recurso, diferentemente de F5, que, embora tenha se formado há apenas um ano, conhece-o superficialmente e não o utiliza. Os fisioterapeutas que utilizam a CAA (F8, F9, F10, F11 e F12) relataram que ela é fundamental para seu trabalho: [...] os resultados na terapia são melhores, os objetivos são alcançados porque a criança tá melhorando a autoestima dela (F12); $O$ paciente passa a participar mais ativamente da sessão [...], aumentando a vontade e o desejo de evolução não só motoramente, mas no seu desenvolvimento global [...] (F11); Eles ficam mais felizes em poder trocar, se comunicar e se fazer entender (F10).

Além da eficácia em seu trabalho, os fisioterapeutas que conhecem e utilizam a CAA demonstraram, com suas respostas, maior sensibilidade durante $o$ atendimento dessas crianças com ECNP. Esse fato pode ser verificado na conceituação da leitura corporal ou nas falas exemplificadas.

\section{Discussão}

A relevância da comunicação na relação do terapeuta com o sujeito em tratamento foi ressaltada por todos os fisioterapeutas entrevistados neste estudo, sobretudo nos casos que demandam a modalidade não verbal. Essa visão está em concordância com o que afirma Mesquita (26) acerca da importância dos sinais não verbais na atuação de profissionais cujos focos são o corpo e o movimento. 0 fato de os fisioterapeutas entrevistados conseguirem efetivar a comunicação não verbal com os sujeitos com ECNP comprova o que o estudo de Campos e Santos (24) encontraram ao afirmarem que os profissionais conseguem perceber o que essas pessoas estão sentindo durante a realização da terapia, mesmo na condição de paralisia cerebral grave, com ausência de oralização de linguagem.

No entanto, também ficou claro nas entrevistas que, apesar de reconhecerem essa relevância, os fisioterapeutas deste estudo não possuem formação teórica para que possam fazer uso científico de tais aspectos em seus atendimentos. Em alguns discursos dos fisioterapeutas, são encontradas contradições referentes ao conflito da teoria com a prática, ou seja, teoricamente todos consideram necessária a interpretação corporal do sujeito com ECNP com oralização restrita ou ausente e relatam que a realizam 
durante a sessão de fisioterapia. Todavia, a maioria afirma ter dificuldades na "leitura" das expressões corporais e faciais desses sujeitos, o que pode ser justificado pela falta de formação adequada no currículo de Fisioterapia para esse tema e para o da humanização. Há várias pesquisas relatando a carência de disciplinas que abordem temáticas vinculadas à humanização nas diferentes instituições de formação de fisioterapeutas $(3,19,22)$.

Ao realizar a análise da grade curricular dos cursos de Fisioterapia do grupo amostral em questão, notam-se currículos tradicionais, embasados em especialidades e pouquíssimas disciplinas humanistas ou voltadas à comunicação com sujeitos com ECNP. Verifica-se que o modelo biomédico embasa tal formação, como já destacado em vários estudos $(3,19)$.

Conforme a legislação vigente, a estrutura curricular, na maioria das universidades, embora com algumas variações de uma para outra, é constituída no primeiro ano por disciplinas consideradas básicas: Anatomia, Fisiologia, Biomecânica e Bioquímica. No segundo ano, iniciam-se as disciplinas direcionadas para a Fisioterapia, como Métodos e Técnicas de Avaliação, Avaliação Funcional, Hidroterapia, Massoterapia, Eletroterapia. 0 terceiro ano é composto, praticamente, de disciplinas aplicadas: Fisioterapia Neurológica, Fisioterapia Ortopédica, Fisioterapia Preventiva e Fisioterapia Cardiorrespiratória, e de aulas práticas específicas por disciplinas aplicadas. E o último ano é caracterizado, principalmente, pelo trabalho de conclusão de curso e pelo estágio supervisionado nas áreas aplicadas (27).

Pode-se notar, portanto, que a medicina ocidental desenvolveu um rigoroso saber sobre o corpo embasado no fisiológico e no anatômico, ou seja, um conjunto de ossos, músculos, sistemas e um receptáculo para diversas patologias (18). A Fisioterapia desenvolve suas estratégias terapêuticas sob uma visão biomecânica do corpo, atuando no segmento corporal acometido - a Fisioterapia Analítica - que trata a parte acometida do corpo para resolver a alteração apresentada (21). E como tal, não constituiu um saber sobre a pessoa, reproduzindo a ideia de que o corpo só pode ser curado mecanicamente, sem a participação ativa do sujeito no tratamento (18).

Essa fragmentação do sujeito gera uma dificuldade do fisioterapeuta em considerar a relação entre corpo e mente, tendo implicação direta na interação durante a sessão de fisioterapia (22).
Por isso, observa-se que o foco dos atendimentos em métodos e técnicas instrumentais fisioterápicas sofisticadas aplicadas ao sujeito, em detrimento da atenção mais humana, abarca a relação interpessoal $(18,23)$. Isso se reflete na diminuição de carga horária das disciplinas destinadas às ciências humanas e sociais e um currículo ainda incapaz de dar conta de uma visão mais integralizada do ser humano, como verificado em alguns cursos, como o da Universidade de Londrina, demonstrando a dificuldade de se desvencilhar da visão tradicional em virtude de resistências internas dos próprios professores da instituição (19).

Para Campos et al. (17), o graduando necessita ter em seu currículo conteúdos que o habilitem a adquirir informações consistentes, abrangendo teorias, técnicas, habilidades, mas também desenvolver sua habilidade de comunicação com o sujeito em tratamento.

A falha na graduação também é relatada em outras profissões da área de saúde, como, na Medicina e na Enfermagem $(28,29)$. Os estudos demonstram que, além da falta de disciplinas relacionadas à humanização, há uma carência na formação dos docentes para poder conduzir tal visão tanto do ponto de vista teórico quanto prático. Na realidade norte-americana, já há uma preocupação em dar conta dessas questões a partir da divisão de que o ensino requer conhecimento, habilidades e atitudes profissionais. Para tanto, os domínios cognitivo, psicomotor e afetivo, no caso da Fisioterapia, devem ser trabalhados $(30,31)$.

Nessa nova perspectiva, a ideia compartilhada por sujeitos, familiares e profissionais, de que o afastamento emocional auxilia a competência para a cura, perde sentido (22), já que a visão global do sujeito com ECNP com oralização restrita ou ausente passa a ser o foco do atendimento. Para atingir tal proposta nos atendimentos, o fisioterapeuta deve, no entanto, ter flexibilidade e não ceder ao trabalho de rotina com foco exclusivo na técnica. Atender a um sujeito demanda lidar com o imprevisível e com novas necessidades a cada atendimento (17). Os entrevistados demonstraram sensibilidade a esse fato ao afirmarem que a intimidade provocada pelo atendimento continuado facilita a leitura corporal. Defendem, portanto, que se preocupar além da lesão, saber mais e melhor da vida do sujeito e criar um contato gradualmente próximo são as formas de humanização da relação terapêutica (19).

Sumiya (18) ressalta seu desconforto com os roteiros preestabelecidos para um diagnóstico, com 
a planificação das queixas clínicas, a utilização em excesso de aparelhos, a impessoalidade, enfim, com a pretensa objetividade que despreza a inegável existência do sensível.

Especificamente, em relação ao quadro de ECNP, embora os entrevistados tenham manifestado certa capacidade de fazer algumas leituras corporais, demonstraram também preocupação com aspectos como dor ou outras necessidades fisiológicas que o sujeito pudesse ter durante a sessão de fisioterapia e que não pudesse comunicar apenas pela modalidade não verbal. Outros aspectos, tais como dificuldades intelectuais ou afetivas, não foram comentados pelos entrevistados, embora tenham sido revelados em alguns estudos como pontos de preocupação de alguns fisioterapeutas, sobretudo as dificuldades intelectuais (3).

Portanto, embora a fala possa estar ausente, o sujeito com ECNP é capaz de manifestar suas intenções por outras modalidades de linguagem, o que não o exclui da relação língua/linguagem (32).

Nesse contexto, diversos autores discutem a importância da leitura da comunicação não verbal (26, 33,34 ) e do uso de recursos de CAA para sujeitos com ECNP com restrição ou ausência de oralidade tanto em situações terapêuticas $(1,10,35)$, como no caso da escola (36) e das situações familiares $(10,37)$.

Observa-se que a maior parte dos entrevistados não conhece a CAA, ou, se conhecem, não a utilizam. Isso, possivelmente, porque ainda há pouca formação especializada sobre o tema no meio acadêmico, na clínica e na área educacional $(13,38)$.

Os profissionais que trabalham com sujeitos com ECNP devem ter uma ação interdisciplinar voltada para o ganho de habilidades motoras e funcionais (7). Dentre os atuantes dessa equipe, os fonoaudiólogos destacam-se com o domínio teórico, a confecção e o uso da CAA por meio de pranchas de baixo custo, como descrito por Cesa (10).

Considerando os resultados de um modo amplo, percebe-se que há interligação importante entre o foco especializado da formação dos fisioterapeutas entrevistadas e o modelo biomédico que exclui reflexões mais amplas relacionadas à vida das pessoas. Esse fato se reflete na quase ausência de preocupação com os processos comunicativos na sessão de fisioterapia, mesmo em situações em que os sujeitos atendidos não podem utilizar a modalidade oral. Há lacunas consideráveis tanto para a formação em leitura corporal quanto para o uso de outras modalidades comunicativas, como a CAA. Ainda, em relação à leitura corporal, que, embora utilizada, está limitada ao elemento cinésico, perde-se de vista o tacésico, que, apesar de amplamente utilizado pelo fisioterapeuta, pelo toque, não élido como sinal comunicativo. Parece estar em questão a diferença entre ver e olhar, ouvir e escutar, tocar e sentir, e mover e gesticular. 0 que delimita tais oposições é que no olhar, escutar, sentir e gesticular tem-se a perspectiva do sentido, ou seja, para sentir é preciso tocar e atribuir um sentido ao toque. A fim de que o fisioterapeuta possa se colocar nesse lugar de sentir, escutar, olhar e interpretar os gestos do sujeito que atende, é preciso formação para considerar o que caracteriza o humano: a linguagem.

\section{Conclusão}

Os resultados deste estudo demonstraram que os fisioterapeutas encontram algumas dificuldades na comunicação com os sujeitos com ECNP, sobretudo pela ausência de recursos alternativos como a CAA ou mesmo pelas limitações na leitura corporal dos sinais não verbais. Esses resultados parecem se relacionar com deficiências na formação profissional, que não contempla tais temáticas, tanto na teoria quanto na prática clínica, por estar centrada predominantemente no modelo biomédico.

Esta pesquisa foi desenvolvida tendo como inspiração o ser humano, seu corpo e sua subjetividade manifestada por expressões corporais, como elementos indissociáveis que encenam histórias e comportamentos múltiplos. Em constantes transformações e de acordo com o mundo em que está inserido, o corpo é o elemento essencial de trabalho da Fisioterapia. Embora suas expressões e "apelos" não verbais ainda não estejam encontrando sua mais ampla leitura, os tempos atuais exigem um fisioterapeuta mais humanizado e com visão mais integrada do sujeito em tratamento. Os resultados do estudo apontam para tal demanda e indicam que uma nova formação, centrada na humanização, faz-se necessária.

Nesse sentido, pesquisas futuras podem refinar o ensino e aperfeiçoar o profissional, beneficiando o atendimento fisioterápico. Para tanto, é necessária uma visão clara da diferença entre aplicar técnicas e ser (fisio)terapeuta na formação do graduando. É preciso enfocar o aprendizado não apenas das técnicas e dos métodos instrumentais, mas também 
das habilidades que se deve ter ao atender um ser humano e como ele se constitui.

\section{Referências}

1. Mendes ANO, Rocha PC, Galdino TR. A efetividade e aceitabilidade da comunicação alternativa e/ou aumentativa em crianças com neuropatia crônica não progressiva - rumo à inclusão. IV Seminário Internacional Sociedade Inclusiva Propostas e Ações Inclusivas: impasses e avanços, Belo Horizonte; 2006.

2. Himmelmann K, Beckung E, Hagberg G, Uvcbrant P. Gross and fine motor function and accompanying impairments in cerebral palsy. Dev Med Child Neurol. 2006;48(6):41723. doi:10.1017/S0012162206000922.

3. Ribeiro J, Moraes MVM, Beltrame TS. Tipo de atividade e relação interpessoal estabelecida entre fisioterapeuta e criança com paralisia cerebral no contexto de intervenção fisioterapêutica. Dynamis. 2008; 1(14):89-95.

4. Mota AP, Pereira JS. Influência da fisioterapia nas alterações motoras em crianças com paralisia cerebral. Fisioter Bras. 2006;7(3):209-12.

5. Silva MS, Daltário SM. Paralisia cerebral: desempenho funcional após treinamento da marcha em esteira. Fisioter Mov. 2008;21(3):109-115.

6. Christofoletti G, Hygashi F, Godoy ALR. Paralisia cerebral: uma análise do comprometimento motor sobre a qualidade de vida. Fisioter Mov. 2007;20(1):37-44.

7. Rotta NT. Paralisia cerebral, novas perspectivas terapêuticas. J Pediatr. 2002;78(1):107-15.

8. Zanini G, Cemin NF, Peralles SN. Paralisia cerebral: causas e prevalências. Fisioter Mov. 2009; 22(3):375-81.

9. Falkman KW, Sandberg AD, Hjelmquist E. Preferred communication modes: pre linguistic and linguistic communication in non-speaking preschool children with cerebral palsy. Int J Lang Commun Disord. 2002;37(1):59-68. doi:10.1080/13682820110096661.

10. Cesa CC. A comunicação aumentativa e alternativa em uma perspectiva dialógica na clínica de linguagem [dissertação]. Santa Maria: Universidade Federal de Santa Maria; 2009.
11. Vasconcelos R. Paralisia cerebral e comunicação alternativa e suplementar: linguagem em funcionamento. Temas desenvolv. 2001;10(58-9):79CE-84CE.

12. Paula KMP, Enumo SRF. Avaliação assistida e comunicação alternativa: procedimentos para a educação inclusiva. Rev Bras Ed Esp. 2007;13(1):3-26. doi:10.1590/S1413-65382007000100002.

13. Cesa CC, Ramos-Souza AP, Kessler TM. Novas perspectivas em comunicação suplementar e/ou alternativa a partir da análise de periódicos internacionais Rev CEFAC. 2010; 12(5):870-80. doi:10.1590/ S1516-18462010005000102.

14. Salmória JG, Camargo WA. Uma Aproximação dos signos - Fisioterapia e Saúde - aos aspectos humanos e sociais. Saúde e Soc. 2008;17(1):73-84. doi:10.1590/ S0104-12902008000100007.

15. Almeida ALJ, Guimarães RB. O lugar social do fisioterapeuta brasileiro. Rev Fisioter Pesq. 2009;16(1):82-8.

16. Rodrigues RM. A fisioterapia no contexto da política de saúde no Brasil: aproximações e desafios. Rev Perspectiva Online. 2008;2(8).

17. Campos BCP, Caromano FA, Tanaka C, Campos TCP. Detecção e descrição das habilidades profissionalizantes na relação fisioterapeuta-paciente durante massoterapia clínica. Fisioter Mov. 2009;22(1):113-9.

18. Sumiya A. Mudanças curriculares e a noção de corpo no curso de fisioterapia da universidade estadual de Londrina. Rev Bras Est Pedag. 2009;90(224):160-75.

19. Sumiya A, Jeolás LS. Processos de mudança na formação do fisioterapeuta: as transições curriculares e seus desafios. Acta Sci Human Soc Sci. 2010;32(1):47-53.

20. Braz MM. Educação integral: um modelo de ensino da fisioterapia baseado na física quântica [tese]. Florianópolis: Universidade Federal de Santa Catarina; 2006.

21. Tessitore EC. Os talentos do corpo: uma experiência de trabalho corporal com pacientes com transtorno mental [dissertação]. São Paulo: Programa de pós-graduação da escola de enfermagem da Universidade de São Paulo; 2006.

22. Canto CRE, Simão LM. Relação fisioterapeuta-paciente e a integração corpo-mente: um estudo de caso. Psicol Cienc Prof. 2009;29(2):306-17. doi:10.1590/ S1414-98932009000200008. 
23. Rezende M. Avaliação da inserção do fisioterapeuta na saúde da família de Macaé/RJ: a contribuição deste profissional para a acessibilidade da população idosa às ações de saúde da equipe: um estudo de caso [dissertação]. Rio de Janeiro: Fundação Oswaldo Cruz; 2007.

24. Campos DC, Santos MG. Sentimentos vivenciados por fisioterapeutas no atendimento a pessoas com paralisia cerebral. Psico USF. 2009;14(2):229-36.

25. Minayo MCS. O desafio do conhecimento: pesquisa qualitativa em saúde. São Paulo: Hucitec; 2008.

26. Mesquita RM. Comunicação não verbal: relevância na atuação profissional. Rev Paul Educ Fis. 1997; 11(2):155-63.

27. Narciso ALG. Corpos em evidência: reflexões sobre a exposição corporal no curso de fisioterapia [dissertação]. Sorocaba: Universidade de Sorocaba; 2006. PMCid:1764017.

28. Lamper JB. Currículo de graduação e o contexto da formação do médico. Rev Bras Educ Med. 2001;25 (1 Supl1):63-9.

29. Almeida DV, Chaves EC. O ensino da humanização nos currículos de graduação em enfermagem. Einstein. 2009;7(3):271-78.

30. Jette DU, Bertoni A, Coots R, Johnson H, Mclaughlin C, Weisback C. Clinical instructors perception of behavior that comprise entry-leval clinical performance in physical therapist students: a qualitative study. Phys Ther. 2007;7(87):833-43. doi:10.2522/ptj.20070003.

31. Jette DU, Portney LG. Construct validation of a model for professional behavior in physiotherapy students. Phys Ther. 2003;83(5):433-43.

32. Chun RYS. Comunicação suplementar e/ou alternativa: abrangência e peculiaridades dos termos e conceitos em uso no Brasil. Pró-Fono R. Atual. Cient. 2009;21(1):6974. doi:10.1590/S0104-56872009000100012.
33. Silva LMG, Brasil VV, Guimarães HC, Savonitti BH, Silva MJP. Comunicação não verbal: reflexões a cerca da linguagem corporal. Rev latino-am. enfermagem. 2000;8(4):52-8.

34. Araújo MMT, Silva MJP, Puggina ACG. A comunicação não verbal enquanto fator iatrogênico. Rev Esc Enferm. 2007;41(3):419-25. doi:10.1590/ S0080-62342007000300011.

35. Deliberato D. Uso de expressões orais durante a implementação do recurso de comunicação suplementar e alternativa. Rev Bras Educ Espec. 2009;15(3):369-88. doi:10.1590/S1413-65382009000300003.

36. Binger C, Light J. Demographics of preschoolers who require AAC. Lang Speech Hear Serv Sch. 2006; ND(37):200-9.

37. Deliberato D, Lopes MAC. Análise da fala de famílias de alunos deficientes não-falantes a respeito da comunicação de seus filhos em ambientes naturais. Rev Extensão Pesq Educ Saúde. 2007;7(3):113-8.

38. Medina EC, Andrade MS. A abordagem psicopedagógica na intervenção fisioterapêutica em criança com encefalopatia crônica não-progressiva. Cad Psicopedagia. 2004;3(6):54-69.

Recebido: 28/04/2011

Received: 04/28/2011

Aprovado: $16 / 12 / 2011$

Approved: 12/16/2011 